\title{
El «país indiviso». Derechos de propiedad y relaciones sociales en Los Llanos de La Rioja, siglos XVIII y XIX/
}

\author{
The «Undivided Country». Property rights \\ and social relationships in Los Llanos (La Rioja, Argentina) \\ XVIIIth and XIXth Centuries
}

\author{
Judith Farberman \\ Universidad Nacional de Quilmes \\ $\mathrm{CeHCMe/CONICET}$
}

Los campos comuneros son propiedades rurales de uso colectivo cuyo acceso es legitimado a partir del parentesco entre sus pobladores. Se asume que sus orígenes son coloniales y todavía hoy constituyen un tipo de propiedad ampliamente difundida en la región de estudio. Este artículo se propone explorar el surgimiento y el devenir de la propiedad indivisa hasta 1800, plantea una periodización del proceso e indaga en las prácticas de los comuneros a través del desarrollo de cinco ejemplos.

Palabras ClaVE: Derechos de propiedad; Los Llanos de La Rioja; Campos comuneros.

«Campos comuneros» (also called «mercedes») are collective properties based on kinship, that still continue to exist in Los Llanos region. The purpose of this article is to provide an interpretation of the emergence and fate of this kind of agrarian structure until the XIX Century and to propose a periodization of the process and an explanation of commoner s social practices.

Keywords: Property Rights; Los Llanos de La Rioja; Land Tenure. 


\section{JUDITH FARBERMAN}

«Estas numerosas poblaciones, desparramadas a ambas orillas a lo largo del río, fueron desalojadas por los conquistadores para hacer de las tierras de labor estancias y propiedad de algún capitán, acaso de apellido Tello, pues a los Tellos pertenece hoy aquel país indiviso y semillero de pleitos» (D.F. Sarmiento, Biografía del Chacho1898, 83).

La región de Los Llanos, en el sudeste de La Rioja, es habitualmente recordada como epicentro de las montoneras del siglo XIX y cuna de los arquetípicos caudillos Facundo Quiroga y Chacho Peñaloza. La cita de Sarmiento añade una referencia quizás menos conocida, la de «país indiviso», fuente de conflictividad a un tiempo agraria y política. Aunque Sarmiento no se explayó sobre ese punto, indudablemente aludía al sistema de propiedad hegemónico en la región: la comunera. ${ }^{1}$ Los Tellos, antiguos conquistadores y presentes poseedores, trazaban una genealogía colonial para aquella peculiar estructura agraria.

Las evocaciones coloniales de los campos comuneros no resuenan tan sólo en Sarmiento. Pierre Denis, que recorrió la zona en 1920, los llamó «mercedes», reconociéndoles una conformación temprana. ${ }^{2}$ En una insuperable descripción del paisaje llanista — que parecía congelado en el tiempo desde el siglo anterior- Denis caracterizó a la «mercedes» por su mayor antigüedad, su localización al pie de los cerros y su orientación pastoril. En contraste, existían en Los Llanos algunas tierras de regadío individuales así como «estancias» situadas en las llanuras, de fundación más reciente.

Determinantes geográficos y técnicos se conjugaban para explicar el predominio de las «mercedes» en las zonas de vieja ocupación. Los Llanos, en efecto, conforman una región extremadamente árida y era en el borde de las sierras (o «costas») donde mejor podían aprovecharse las escasas lluvias orográficas y el caudal de los ríos y vertientes. Mientras en la llanura la represa artificial solía ser la única reserva acuífera, en las costas predominaban las aguadas naturales, favoreciendo la invernada de los

1 En los documentos del siglo XVIII — fuentes que aportan al núcleo de esta investigaciónsólo se utiliza una vez el término «comunidad de campos». Así pues, la expresión «campo comunero» en contexto colonial nos pertenece y remite sobre todo a un conjunto de prácticas y a inferencias basadas en testimonios posteriores. En contraste, los términos «propiedad comunera», «campo común» y «propiedad indivisa» aparecen con frecuencia en materiales de la segunda mitad del siglo XIX y todavía hoy se utilizan. Por último, en el siglo XX es habitual el uso del término «merced» como sinónimo de propiedad comunera, tanto en Los Llanos riojanos como en otras zonas del noroeste argentino. Para evitar confusiones con la institución colonial de la merced, utilizaremos comillas cuando el sentido del término sea equivalente al de «campo comunero».

2 Denis 1987 (1920). 


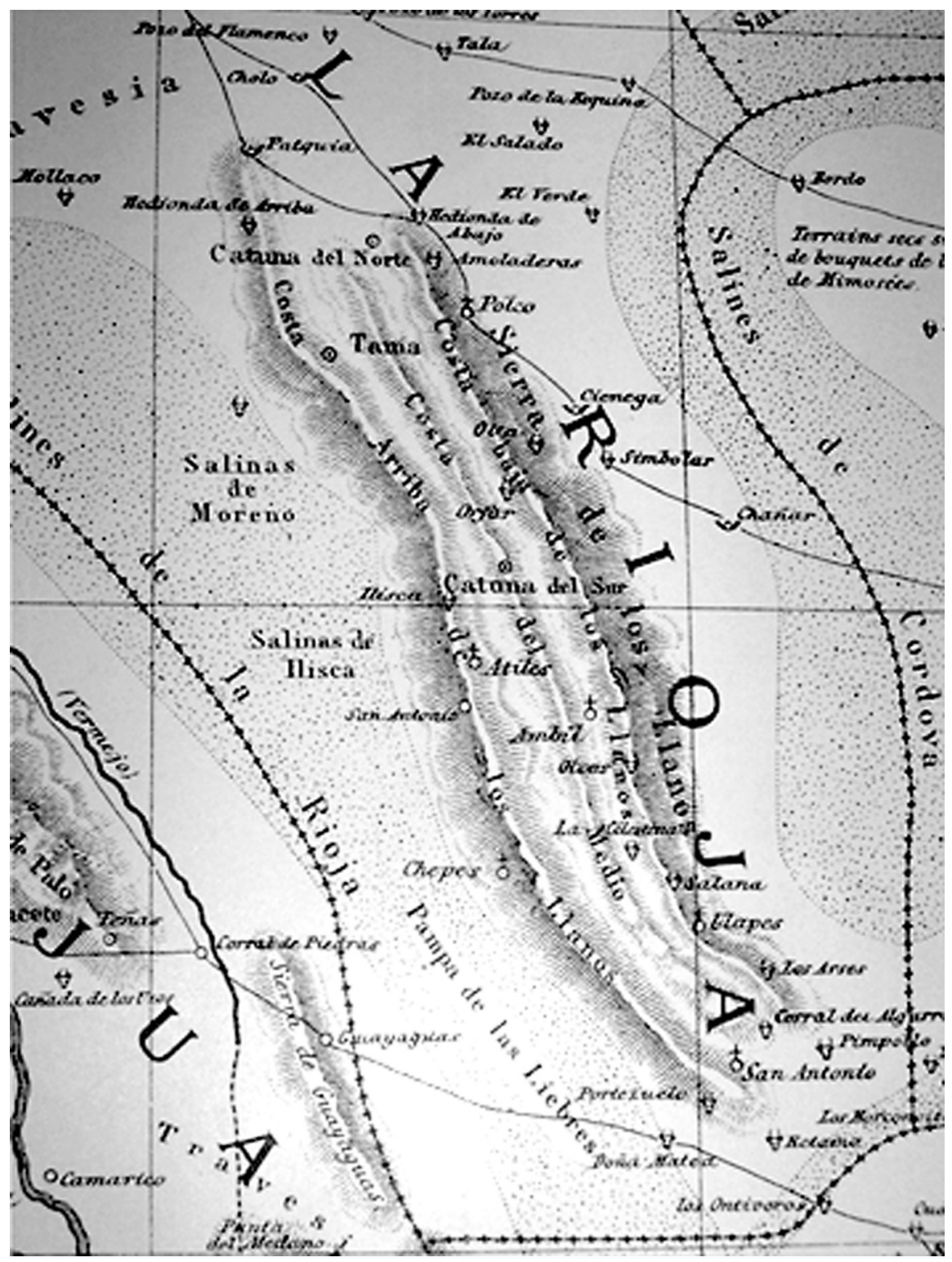

La región de Los Llanos según el mapa de Víctor Martín de Moussy, publicado en el atlas que acompañara su Descripción de la Confédération Argentine (1867). 
animales. Entre otros factores, este sistema de manejo del ganado desalentaba el cercamiento y la división hereditaria de las «mercedes». Así, cuando los propietarios no eran numerosos, era posible conocer «los lazos de parentesco que existen entre ellos y el valor de los derechos de cada uno», caso contrario, solía perderse «[...] la noción exacta de la parte de la merced a la que cada uno tiene derecho», mezclándose «herederos legítimos y usurpadores». ${ }^{3}$

Nada dice Denis sobre la transferencia de la propiedad indivisa. Por otras fuentes, sabemos que, al igual que hoy, eran la herencia y compraventa de derechos y acciones sobre tierras y aguas las que regulaban el acceso. La multiplicación de tales transferencias fue progresivamente dispersando los derechos sobre la tierra, un fenómeno ya muy notable en los tiempos de Chacho Peñaloza. ${ }^{4}$ De esta suerte, los condominios extendían «una red invisible y casi infinita de relaciones entre comuneros [....] cuya influencia en las prácticas sociales es difícil de calcular» y que, evidentemente, adquirió un preciso contenido político en el siglo XIX. ${ }^{5}$

No obstante los orígenes coloniales atribuidos a las «mercedes», no conocemos trabajos que expliquen la génesis de su uso en común en la región. Sabemos de su larguísima perduración y también de su presencia extendida en el norte argentino, pero casi nada sobre la gestión de la propiedad comunera. ${ }^{6}$ Lo que esta contribución se propone es develar el surgimiento de esta estructura agraria en el contexto del proceso de poblamiento llanista del siglo XVIII, postular una periodización de este proceso y, hasta donde es posible, indagar en las prácticas de los comuneros.

Indudablemente, también en Los Llanos la merced fue un instrumento fundamental en la formación de la propiedad privada durante la colonia. Sin embargo, esto no significa que la indivisión fuese el destino ineludible de las mercedes; de hecho, éstas fueron originariamente asignadas a propietarios exclusivos y el desmembramiento de las grandes estancias primitivas fue habitual hacia principios del siglo XVIII. ¿Por qué motivos, entonces, en un momento dado, aquellas estancias devinieron campos comuneros? ¿Y cómo afrontaron los condóminos las presio-

3 Denis 1987 (1920), 102.

4 De la Fuente 2007, 97-98.

5 De la Fuente 2007, 98.

6 Sobre la propiedad comunera en Los Llanos en el siglo XX, Olivera 2000 y el informe anónimo del CFI 1964. Para Córdoba, y en vinculación con la propiedad común de pueblos de indios, Tell, 2010 y 2011. Sobre campos comuneros actuales en Catamarca, Zubrzycki 2002. 
nes individualizadoras que, también en esta región, se hicieron sentir intensamente?

Podemos anticipar una hipótesis: que los campos comunes fueron construyéndose sobre un conjunto de prácticas que alumbraron una suerte de derecho campesino, alternativo al que prohijaban los nuevos tiempos económicos e institucionales desde mediados del siglo XVIII. Tales prácticas sólo resultan visibles en coyunturas conflictivas y es por eso que lo sustancial de nuestro corpus proviene de litigios por tierras. También utilizaremos dos censos de población —uno de 1767 y otro de 1795- y un completo informe del curato de 1805 .

Nuestro recorrido se iniciará periodizando el poblamiento del curato y presentando a sus actores para profundizar posteriormente en la coyuntura inaugurada a fines de la colonia, coyuntura de redefinición y confrontación de derechos de propiedad. La segunda parte del artículo reduce la escala de análisis para concentrarse en cinco ejemplos, tres ilustrativos de conflictos con personajes externos y dos que alertan sobre las divisiones que podían suscitarse entre los mismos condóminos.

\section{Una periodización del poblamiento en Los Llanos coloniales}

La historia colonial de Los Llanos precede la de La Rioja ya que parte de sus habitantes originarios fueron apropiados a través de malocas por vecinos de San Luis y de Córdoba. Una vez fundada la capital en 1591, el poblamiento hispano priorizó las tierras cercanas y muy especialmente los oasis del oeste, mejor favorecidos por el agua y el asentamiento nativo. En contraste, además de árida y despoblada, nuestra zona se encontraba todavía al margen de los principales circuitos comerciales.

Así y todo, algunas encomiendas fueron repartidas en el siglo XVII, generalmente entre miembros secundarios de la élite. ${ }^{8}$ Aunque es posible que varios de los pueblos de indios asignados no llegaran jamás a constituirse como tales, dejaron desde temprano dos marcas indelebles en el paisaje: un conjunto de topónimos y una referencia de superficie para delimitar las mercedes («dos leguas de contorno», medidas desde la aguada

7 Las referencias de los litigios serán indicadas en cada caso. El padrón de 1767 se halla en AHC, 2.37.21 y el de 1795, junto con el informe de 1805, en AAC, leg. 20, t. 2.

8 En Los Llanos existieron cuanto menos 13 pueblos de indios en el siglo XVII. Sin embargo, hacia 1693, fecha de la visita del oidor Martínez Luján de Vargas, solamente perduraban tres: Olta, Atiles y Colosacán. Ver al respecto Boixadós y Farberman, 2009 y 2011. 
principal o la plaza). Y, bien que estos títulos no conllevaron en su momento radicación hispana alguna, se cotizaron en el siglo siguiente cuando su antigüedad y la imprecisión de los confines de la propiedad resultaron cartas victoriosas en las disputas por tierras que acompañarían el ascenso económico de Los Llanos.

Por tanto, los apellidos paradigmáticos de la región se remontan al siglo XVIII, apuntando a dos perfiles sociales contrapuestos: el de los «señores» y el de los «soldados». Los primeros, sujetos de cierto peso local (e incluso regional), adquirieron por compra los viejos títulos de merced de la primera oleada antes de 1750. Estos señores no tenían méritos militares que lucir pero sí firmes intenciones de hacer negocios con la cría y el comercio de ganado. Fue éste el caso de don Francisco Peñaloza, que en 1742 se hizo con la vasta propiedad de Tuani, o de Pedro Antonio Ávila, titular de Malanzán y suegro del primero que afianzaron su pertenencia en la región desposando a mujeres locales. ${ }^{9}$

Sin embargo, el perfil típico del poblador llanista es el del soldado. Las trayectorias de Antonio Reynoso Tello, Josep Roldán y Juan Ruarte - que conoceremos en breve - entran ajustadamente en esta categoría, que incluía a españoles pobres, mestizos, e incluso a algunos indios, humildes participantes de las entradas al Chaco, que recalaban en la región para «valer más». ${ }^{10}$

Señores y soldados disponían de títulos individuales sobre sus tierras. Ello no impidió que, ya en esta etapa relativamente temprana, unos y otros procuraran incrementar o asegurar efectivamente sus patrimonios colonizando aguadas situadas en el realengo o contenidas en las primitivas mercedes. En un reclamo dirigido al Cabildo, el soldado Juan Barrionuevo señalaba los roces que podían derivarse de estos movimientos. Si él no podía disfrutar plenamente de sus tierras era porque sus vecinos «continua-

9 Los Ávila conformaban una antigua familia riojana del segundo círculo de la élite, con algunos propietarios de pequeñas encomiendas. En cuanto a Francisco Peñaloza, es probable que naciera en Los Llanos. De hecho, su padre Josep — quizás peninsular — ya vivía en Malanzán con su esposa en 1744. En estos años, Pedro Antonio Avila y Francisco Peñaloza eran típicos «señores llanistas»: miembros marginales de la élite de la capital pero con fuerte peso local, que afianzaron en matrimonios múltiples.

10 Los términos en que estos soldados solicitaron sus mercedes y el carácter modesto de los premios dicen bastante sobre ellos. En su petición, Juan Barrionuevo sostenía haber «padecido indecibles trabajos y molestias de estancia en estancia, de casa en casa, experimentando voluntades ajenas por no tener hogar ni casa propia» (AHPC, 2.73.24) mientras que Josep Flores, en sentido similar, afirmaba hallarse hasta el momento «divagando y peregrinando sin saber dónde hacer mansión y casa de no tener un rincón donde morar» (AHPC, 2.27.16). 
mente andan formando derecho» a partir de sus prácticas, como él mismo lo había hecho antes de solicitar su merced. ${ }^{11}$

No obstante, es sin dudas el tercer momento — que arranca hacia 1750 pero que señala picos de conflictividad a fines del siglo XVIII y principios del XIX - el que resulta crucial para comprender tanto los procesos de conformación de los campos comuneros como las ofensivas individualistas que los amenazaron. Podemos identificar tres estímulos principales que -en un contexto de ascenso económico regional- motorizaron los cambios.

Quizás el más importante fue la incorporación de Los Llanos a un circuito más amplio de cría y venta de ganado, que encontraba en la zona mineras del Norte Chico chileno su principal mercado. Según Silvia Palomeque, los actores típicos del nuevo escenario eran pequeños productores campesinos, como nuestros soldados llanistas. ${ }^{12}$ Aunque también participaran de estos tráficos personajes de envergadura, no parecen haber sido protagónicos.

El segundo incentivo fue el sustancial incremento demográfico: si en 1767 la población del curato alcanzaba los 1.732 habitantes, en 1795 se había duplicado, trepando a 3.475, todos concentrados en las «costas». Las cicatrices de este poblamiento acelerado son visibles en la ocupación de «nuevas» aguadas, en el aumento de la participación de familias extensas y múltiples y, sobre todo, en la multiplicación de individuos clasificados como «agregados», que alcanzaban en 1795 al 25\% de la población empadronada. ${ }^{13}$ La baja relación de masculinidad para las cohortes activas y una percepción más conservadora de la sociedad, transparente en las clasificaciones socioétnicas que nos dejó el autor del padrón de 1795, don Sebastián Cándido de Sotomayor, también son signos del cambio. ${ }^{14} \mathrm{Y}$ no solamente los tenidos por españoles habían disminuido su participación entre los habitantes del curato: el censista se había permitido rebajar la calidad social de unos cuantos orgullosos y pioneros soldados.

Finalmente, el tercer estímulo es de orden institucional: nos referimos a la Real Instrucción de 1754, que disponía la regularización frente a las justicias locales de los títulos de propiedad posteriores a $1700 .{ }^{15}$ Los efectos de esta cédula se hicieron sentir en Los Llanos hacia 1780, provocando

11 AHPC, 2.72 .24 (itálica mía).

12 Palomeque 2006.

13 Boixadós y Farberman 2009a.

14 Boixadós y Farberman 2009b.

15 Sobre el contenido de la Instrucción, considerada paradigmática de las políticas borbónicas, Mariluz Urquijo 1968, 41 y 60; Ots Capdequí 1946, 115-116. Sobre su aplicación en Los Llanos, Boixadós 2009. 
litigios entre los antiguos poseedores y los nuevos aspirantes - a menudo hombres de la élite riojana, puntana o sanjuanina, con influencias en el cabildo y buen acceso a la información - que denunciaron como vacantes tierras pobladas desde antiguo. ${ }^{16}$

En resumen: hacia fines del siglo XVIII, una combinación de factores económicos, institucionales y demográficos produjo una compleja y delicada situación que afectó particularmente a las familias pioneras. Entendemos que, para entonces, las aguadas llanistas habían crecido por encima de sus posibilidades ambientales y que, por lo menos desde el primer tercio del siglo XVIII, menguadas ya las posibilidades de «formar derecho» en tierras realengas, compartir el campo resultó más funcional que subdividirlo entre los herederos. En otras palabras, y como lo evocan intensamente los padrones de población, la propiedad comunera ya era una realidad de hecho a fines del Setecientos. Por otro lado, las exigencias de regularización de la cédula implicaban un nuevo reparto de las barajas en el que los conflictos, lejos de librarse entre propietarios individuales, involucrarían en muchos casos a nutridos grupos de condóminos.

La disolución de los pueblos de indios de Colosacán y Atiles formó parte de este mismo proceso tardocolonial. Sin embargo, la erosión de las estructuras corporativas venía desde antes y revestía una especificidad propia, visible en el temprano predominio de los «agregados» del pueblo sobre sus moradores legítimos. ¿Tenían los indios tributarios y los condóminos de las «mercedes» formas similares de gestionar sus recursos o de organizar las relaciones internas entre sus miembros? Probablemente no. De hecho, los pueblos de indios llanistas se disolvieron sin más (con el alejamiento de la mayoría de los tributarios y el descenso de otros al mundo de los «agregados») mientras que los condóminos enfrentaron o negociaron con quienes, a partir de sus denuncias atendidas, se pretendían nuevos dueños de las tierras. De esta manera, los campos comunes de Los Llanos se demostraron como estructuras mucho más sólidas y perdurables que sus pueblos de indios, desprovistos desde temprano de caciques y siempre raleados de su población «legítima». ${ }^{17}$

16 La regularización de los títulos no sólo involucraba a los propietarios o poseedores sino también a los vecinos colindantes, que también debían exhibir sus papeles a fin de comprobar los linderos de las propiedades. De esa manera, a los problemas ocasionados por títulos extraviados, deteriorados o inexistentes se sumaron nuevas complicaciones — que a menudo reavivaban conflictos latentes- derivadas de la superposición de límites o ausencia de mensuras.

17 En contraste con lo sucedido en otras jurisdicciones tucumanas como Córdoba y San Miguel de Tucumán, donde algunas «comunidades» sobrevivieron hasta fines del siglo XIX. Ver Fandos, 2007 y Tell, 2010a y b. 


\section{De la propiedad individual a la propiedad colectiva}

Los padrones de población de 1767 y 1795 ofrecen una suerte de «mapa» de la ocupación llanista y también una primera semblanza de la estructura agraria. Ya se aludió a la duplicación de la población y de los topónimos, así como al abigarramiento de las «casas» por recepción de parientes y de «agregados» pero también otras transformaciones son perceptibles. Así, si el censo de 1767 evoca intensamente la imagen de homogéneas comunidades de parientes, en 1795 tal uniformidad es menos evidente y, además de la mayor dispersión geográfica de varios apellidos paradigmáticos, se registran otros nuevos, portados tanto por sujetos honrados con el «don» como tildados de «agregados». También son novedosos la formación de grupos de dependientes de propietarios ausentistas y la «democratización» de ciertos apellidos como Mercado, Peñaloza o Argañaraz.

Por cierto, nada explicitan estos conteos sobre los derechos de propiedad ni sobre el carácter realengo o privado, exclusivo o común de los campos. Es su cotejo con otras fuentes el que nos permite integrar la cuestión agraria, además de imprimirles movimiento a estas postales. Antes de profundizar en los cinco casos que mejor conocemos, aclaremos algunas premisas e hipótesis que hacen a nuestra lectura de datos generalmente residuales y dispersos en las fuentes.

En primer lugar, el concepto mismo de campo común, en sus tres significados. ${ }^{18}$ El primero es similar al actual: propiedad privada indivisa, legitimada en buena medida por el parentesco entre los compartes. En este sistema, sólo los pastos - y tal vez las aguadas - eran utilizados conjuntamente. La segunda acepción remite a tierras realengas usufructuadas por propietarios de uno o más campos comunes. Se trataba de terrenos intersticiales, generalmente boscosos, que pasaron a ser objeto de disputa entre los pobladores una vez que la ganadería mercantil se afianzó en Los Llanos y los condóminos procuraron «formar derecho» en ellos. Por fin, la tercera acepción remite a los pueblos de indios, sobre los que se han aportado ya las necesarias referencias. Estos tres sistemas no constituían compartimientos estancos y los condóminos bien podían tener derechos - amparados por títulos o habilitados por la costumbre- en todos ellos a la vez.

En segundo lugar, contamos con algunos indicios para sostener que ya a fines de la colonia existía una cierta dispersión de derechos en los

18 Nos referimos a los significados que las palabras de los actores involucrados en los juicios nos permiten inferir. Una vez más, estamos haciendo hincapié en las prácticas concretas. 
campos comunes: de aquí la comentada diseminación y «democratización» de apellidos paradigmáticos. También por ese motivo, los reclamos solían ser conducidos por sujetos letrados que, sin residir en los condominios, mantenían en ellos sus derechos (extensivos a su cónyuge e hijos). En cambio, aunque quizás alguna forma embrionaria se gestara en estos años, no tenemos noticias de que existiera entonces un mercado de derechos y acciones antes de la mitad del siglo XIX.

En tercer lugar, no obstante la dispersión de derechos, una identidad cierta fue creándose entre ciertas familias y «sus» lugares. La endogamia matrimonial - que intuimos en los censos pero que habría que corroborar estudiando los registros parroquiales - contribuyó seguramente a fortalecer sentimientos de pertenencia y comunidad. Por este motivo, la historia de los campos comuneros es también la de sus «casas» multigeneracionales, asociaciones perdurables entre paisajes y gentes.

El final del siglo XVIII auspiciaba transformaciones en la estructura agraria. Pleitos y padrones nos permiten imaginar al menos tres situaciones, expresivas todas del ascenso económico regional. La primera es la de consolidación de ciertos campos comunes, aunque quizás bajo nuevas condiciones: en la medida en que el contexto de cierre (temporario) de la frontera agraria limitó las posibilidades de colonizar nuevos sitios, las familias llanistas se abigarraron en sus tierras y ya no las desmembraron a través de la subdivisión hereditaria. Los Tello de Chepes y de Ulapes podrían ejemplificar esta situación y también los Ruarte y los Aguilera de Chelcos y Toro Muerto, que terminaron preservando su «comunidad de campos».

La segunda situación implicó el tránsito hacia la propiedad exclusiva. En este sentido, los pleitos señalan un avance indudable de concentración de tierras, que encontró su amparo legal en la Real Instrucción de $1754 .{ }^{19}$ Fue así que un grupo de hombres fuertes cuestionó los derechos de antiguos pobladores que no habían reclamado oportunamente la composición, o que tenían títulos dudosos o deteriorados. La apropiación de Macasín por parte de Prudencio Quiroga, la de Solca por don Gualberto de la Vega, la de Santa Rosa por Bernardino Fernández Cabezas y, aunque con su especificidad, la de Atiles por don Nicolás Peñaloza responderían a este patrón.

19 Desde la Historia del Derecho se ha señalado que la aplicación de la Real Instrucción de 1754, al no fijar un límite máximo a las ventas de tierras, facilitó la adquisición de grandes extensiones, especialmente en el Litoral y Banda Oriental, Mariluz Urquijo 1968, 41. Asimismo, también se ha identificado su aspiración individualista (Ots Capdequí 1946, 112) y, más en general, hostil a la costumbre. Como veremos, en los ejemplos que se analizan en este trabajo, no es la comunidad lo que está en discusión sino la validez de los títulos individuales que posteriormente habían dado origen a condominios prácticos. 
No es, sin embargo, improbable que los flamantes dueños iniciaran nuevos condominios y tampoco faltan ejemplos de pobladores despojados que se mantuvieron en las tierras de sus mayores, eventualmente como agregados. Como sea, a mediados del siglo XIX eran escasas las propiedades exclusivas lo que permite pensar que la desarticulación de una comunidad no implicaba en modo alguno la de un perdurable sistema.

Por fin, la tercera situación es la de las «víctimas», a menudo descendientes de los soldados pioneros, que conocieron los sinsabores del desclasamiento y la pobreza. Las desventuras de los Roldán y de los Ávila de Solca y Macasín, las de los hijos de Catalina Alcaraz de Salanita, resultaron de la desarticulación de comunidades antiguas, conformadas cuando todavía era posible instalarse en Los Llanos para «valer más». En el nuevo escenario, no extraña que estos campesinos buscaran la protección de vecinos notables que defendieran sus derechos sobre la tierra. Así lo hicieron los «Pobres de Jesucristo» — que acogieron a varios representantes Roldán y Ávila y se asociaron con los Peñaloza - y también los Tello, que hicieron propia la causa de Catalina Alcaraz y se refugiaron en el amparo del párroco Josep Nicolás Ocampo.

Los cinco ejemplos que logramos reconstruir $-\mathrm{y}$ que reseñamos hasta ahora velozmente- dan cuenta de estas tres situaciones..$^{20}$ Todos ellos remiten a por lo menos dos aguadas relacionadas (habitadas por grupos de parentesco diferentes) y así los designaremos. De esta suerte, hemos de ocuparnos de las «casas» localizadas en Solca/ Macasín, Malanzán/Atiles, Ulapes/Salanita, Chepes/Santa Rosa y Chelcos/Toro Muerto.

Salvo en el último caso, las aguadas principales se encontraban en nudos de comunicación estratégicos para los viajeros de las penosas travesías y eran sede de capillas. Otra razón que volvía atractivos estos terrenos era su diversidad ambiental, que podía habilitar una modesta agricultura mediterránea. Aunque los datos sobre la superficie de estas unidades no siempre son confiables, todos nuestros pobladores tenían aseguradas sus porciones de monte y, salvo en las integralmente serranas Macasín y Malanzán, las zonas montañosas convivían con otras de llanura, facilitando la trashumancia del ganado. ${ }^{21}$

20 Para facilitar la lectura de los casos, remitimos al lector al cuadro de síntesis del anexo.

21 Para Solca, Chepes y Ulapes la referencia es de «dos leguas a cada lado»; para Atiles, «una legua a todos los vientos» desde la aguada principal. Contamos con datos contemporáneos (y por ende aún más dudosos) para las restantes «mercedes» algunos parcialmente contradictorios con los conocidos para el siglo XVIII. 
En el mismo sentido, el informe que el párroco don Sebastián Cándido de Sotomayor redactó en 1805 destaca los sitios de Solca, Atiles, Chepes, Ulapes y Malanzán como relativamente más amables en el contexto de la avara geografía llanista. En los tres primeros, localizó a algunas de las fortunas ganaderas del curato (Gualberto de la Vega, Nicolás Peñaloza y Casilda Flores) mientras que destacó del conjunto a Ulapes por «sus guertos de higueras, y algodonales» y a Malanzán por sus «arboledas de Castilla y tres viñuelas». Aunque también en Atiles don Nicolás Peñaloza había plantado una viña, don Cándido juzgaba con escepticismo sus potenciales provechos.

Sin duda, la escasez de agua seguía siendo el factor más dramático en Los Llanos. Solamente las tierras de Atiles y de Malanzán eran atravesadas por ríos y únicamente del antiguo pueblo de indios se afirmaba que el agua era «estable y no suele escasear». En ambos sitios, una red de acequias conducía el exiguo caudal -inexistente en verano- hacia los sembradíos y las casas. Los demás campos sólo contaban con sus aguadas, a veces demasiado salobres, generalmente estacionales y reducidas a meros «sudaderos» o «lloraderos» en Chelcos, Macasín, y Santa Rosa.

Así pues la disponibilidad de agua regía la jerarquía de los diferentes sitios. Ya dijimos que las primeras mercedes fijaban su centro geográfico en la aguada principal, recortando extensiones de una o dos leguas «a cada viento». En estas demarcaciones, solían entrar otras aguadas secundarias o «anejas»; cuando ello no ocurría, fue relativamente común la colonización de las aledañas, sobre todo las localizadas en el realengo. De manera que los vínculos que unían a los sitios elegidos eran de diferente origen y presuponían también relaciones de diversa naturaleza entre sus habitantes.

En este sentido, entendemos que el primer lazo entre Solca y Macasín consistió en su inclusión originaria en una misma merced, concedida hacia 1640 a Agustín Mercado y Reynoso. En 1695, un humilde soldado tucumano llamado Josep Roldán las adquirió por 400 pesos, se instaló con su familia y construyó la capilla del paraje. Treinta años más tarde, el ya anciano Roldán desmembró de su propiedad la aguada de Macasín para dotar a su nieta: desde entonces, las aguadas remiten a dos «casas», la de Roldán y la de Ávila Cartagena. ${ }^{22}$ ¿Conformaban estos grupos parentales una misma comunidad en sus prácticas? No podemos afirmarlo pero sabemos con certeza que un prolongado pleito judicial los encontró juntos en 1786.

22 Boixadós y Farberman 2008, 15. 
También Chepes, Ulapes y Chelcos resultaban de mercedes del siglo XVII vendidas a principios del XVIII. Y el perfil de los compradores no se apartaba demasiado del reseñado para Josep Roldán: soldados pobres, que intentaban hacer pie en algún sitio. Antonio Reynoso Tello —que a diferencia de los otros dos era clasificado sin ambigüedad como españoladquirió Chepes en 1701, pagando una parte con su trabajo personal en Ulapes, otra estancia del vendedor. Once años después, Tello debió renunciar a su propiedad (por el reclamo de un beneficiario más antiguo de la merced) pero fue compensado con Ulapes que, al fin y al cabo, también era obra de sus manos. Quiso el destino que en 1731 Reynoso Tello fuera doblemente propietario, ya que en ese año logró comprar nuevamente la estancia de Chepes, pudiendo así localizar separadamente a los vástagos de sus dos matrimonios y asegurarles una modesta fortuna y dignidad de españoles.

¿Qué sabemos de Salanita y Santa Rosa, vinculadas por dos pleitos tardocoloniales a Ulapes y Chepes como aguadas anejas? Podemos adelantar que la primera (no discriminada en el censo de 1767) fue vendida por Reynoso Tello a un tal Juan Villalta antes de la mitad del siglo. ${ }^{23}$ En contraste, los datos sobre Santa Rosa resultan más dudosos. Ana María Brizuela — viuda de Tello y condómina de Chepes - sostuvo que, con su dote, ella había aportado aquellas tierras al consorcio de su familia política pero no consiguió que ni siquiera sus compartes refrendaran sus dichos. ${ }^{24}$

En cuanto al campo común de Chelcos y Toro Muerto, parece haber sido el menos apetecible de los mencionados hasta aquí. Las descripciones aluden a sus «serranías fragosas», los «pastos escasos y débiles», los «montes espinosos que enbarasan para la cría de ganados y toda especie de animales». Ninguna de sus contingentes aguadas tenía «capacidad para plantíos» y ni siquiera el bosque que «en cuanto a maderas no tiene ningunas» fue valorado como recurso por los tasadores. ${ }^{25}$ Con todo, la aguada de Toro Muerto fue tempranamente objeto de disputa entre el soldado Juan Ruarte - comprador de Chelcos-y su vecino Francisco de Ontiveros, que la pretendía como parte de su propiedad. En 1733, Ruarte reunió una información de testigos que le granjeó la victoria, demostrando que, además de

23 AHPC, 2.71.1. Cabe destacar que, el conflicto que luego comentaremos y que enfrentó a los Tello con don Clemente Galván, denunciante de Salanita, permite suponer que la comunidad no se desmembró con la venta.

24 AHPC, 2.99 .4

25 AHPC, 2.98.94. 
servir al Rey «a su costa y mención» y «aviando más de lo que puede», se hallaba «con bastantes necesidades y en suma cortedad de todo».

Si en estos cuatro casos la «aguada aneja» venía incluida en la merced originaria o había sido «ganada» por diferentes medios, Atiles, espacio soberano de una corporación indígena, representaba una situación diversa. Sin embargo, no sólo por esto la historia de Malanzán/Atiles es singular. Por empezar, el primer comprador de la estancia (en 1700) no era un humilde soldado sino un personaje notable —don Pedro Antonio Ávila-que fue por un tiempo encomendero de Atiles. De sus siete hijas mujeres, cinco se casaron con hombres connotados, aportándole al condominio cierta aura nobiliar. ${ }^{26}$ Por ahora interesa destacar que los avances sobre Atiles se realizaron en dos etapas - la compra en remate del pueblo y la apropiación de sus «sobras»— y que uno de los condóminos — don Nicolás Peñalozaterminó sacando el mayor provecho. ${ }^{27}$

¿En qué momento las estancias adquiridas a principios del siglo XVIII por el «señor» Josep Antonio de Avila y los soldados Roldán, Tello y Ruarte se volvieron condominios? ¿Qué razones nos autorizan a presumir que efectivamente lo fueran?

Es revelador que los únicos desmembramientos aludidos en los pleitos fueran anteriores a 1730 y se debieran a transferencias por venta, por dote o para separar a la progenie de matrimonios sucesivos. Consideramos altamente probable que, después de esa fecha, ya no se realizaran subdivisiones y, por el contrario, los condóminos procuraran «formar su derecho» en las inmediaciones de sus terrenos. Los pleitos apoyan esta idea, ya que se refieren únicamente a las mercedes originales e identifican a los propietarios como «compartes». Pero sobre todo son los padrones de 1767 y 1795 — sumada a información residual de los pleitos- los que invitan a situar la conformación de los condominios después de la segunda mitad del siglo XVIII.

\section{La gran tormenta}

Hemos comprobado hasta ahora que, más allá del origen diferente de los vínculos entre las aguadas principales y sus anejas, la historia de las propiedades reseñadas reconoció una periodización semejante. En todos

26 Boixadós y Farberman 2009b, 97-98.

27 AHPC, 2.56.6 y AGN IX.23.5.6 respectivamente. 
los casos, se trataba de mercedes repartidas en el siglo XVII, vendidas a principios del XVIII y - por lo menos en Solca y Ulapes- desmembradas antes de 1730. Como anticipamos, a fines del siglo XVIII, una verdadera explosión de denuncias sacudió varios de los condóminos de estos campos casi simultáneamente. Así, en 1785, mientras un descendiente del primer beneficiario de la merced de Chelcos amenazaba a la nuera del primer Ruarte con despojarla de las tierras que tanto tiempo atrás habían ingresado al poder de la familia, don Lucas Bazán denunciaba y obtenía la aguada Macasín. Un año más tarde, algunos de los compartes de Solca y Macasín, presentándose junto a otros desposeídos como «Pobres de Jesucristo», sumaban sus reclamos a los de la familia Pereira-Peñaloza, embarcada en un largo pleito con don Josep Antonio Mercado y Reynoso. ${ }^{28} \mathrm{Y}$ los embates siguieron: en 1789 Manuel Fernandez Cabezas reclamó Santa Rosa, en 1790 Clemente Galván hizo lo propio con Salanita y, aunque es incierto el momento en que don Gualberto Vega denunció las tierras de Solca, el censo de 1795 lo encuentra ya instalado en ellas. En 1798 don Nicolás Peñaloza consiguió para sí los campos de Atiles y en 1800 Macasín fue denunciado y obtenido por don Prudencio Quiroga. Por fin, en Chelcos, las denuncias crearon un conflicto interno entre los condóminos hacia 1790, que se saldó amigablemente. Resumiendo: con el ocaso del siglo, movilizados por el ascenso económico regional y agitando la letra de una real cédula por mucho tiempo olvidada, un grupo de denunciantes procuró forzar una redefinición de los derechos de propiedad en Los Llanos de La Rioja. Un terremoto semejante tenía que dejar sus huellas y la comparación de los datos de los padrones de 1767 y 1795 nos permite una primera aproximación. ${ }^{29}$

Por cierto, no sorprende demasiado que en las aguadas principales el incremento demográfico sea consistente, ya que sigue el movimiento general del curato. También se verifica en todos los casos (con la excepción de Toro Muerto) la complejización de las «casas» merced a la recepción de agregados.

Sin embargo, otros datos se apartan de esta tendencia. Así, en dos de las tres aguadas anejas consideradas (Santa Rosa y Salanita), en Macasín y en el pueblo de indios de Atiles no sólo la población disminuye sino que, en buena proporción, sus habitantes están agregados a las «casas» (o a un

28 Boixadós y Farberman 2011.

29 Para facilitar la lectura de la evolución de los campos comunes estudiados y de los intrincados conflictos que tuvieron lugar, remitirmos al lector al cuadro resumen del Anexo. 
propietario residente en otro sitio -Nicolás Peñaloza-, como ocurre en Atiles). Sabemos con certeza que en aquellos cuatro sitios se producen procesos de despojo en los que reconocemos cierta variabilidad: proponemos que en Salanita y Macasín se transitó hacia la propiedad exclusiva y que algo similar sucedió en Solca. El caso de Santa Rosa es más dudoso, mientras que las vicisitudes de los pobladores de Atiles, por su carácter de indios tributarios, revisten una especificidad propia.

\section{POBLACIÓN, UNIDADES DOMÉSTICAS Y AGREGADOS \\ EN UNIDADES ELEGIDAS}

\begin{tabular}{lrrcrrc} 
& \multicolumn{3}{c}{1767} & \multicolumn{3}{c}{1795} \\
& Total & $J F$ & Agregados & Total & JF & Agregados \\
\hline Solca & 12 & 3 & 0 & 20 & 4 & 5 \\
Macasín & 30 & 8 & 0 & 22 & 2 & 14 \\
Chepes & 26 & 4 & 5 & 74 & 11 & 19 \\
Santa Rosa & 20 & 4 & 0 & 16 & 1 & 8 \\
Ulapes & 22 & 6 & 6 & 53 & 5 & 14 \\
Salanita & 23 & 5 & 0 & 17 & 1 & 15 \\
Malanzán & 87 & 10 & 16 & 185 & 20 & 44 \\
Atiles & 71 & 12 & 6 & 10 & 1 & 6 \\
Chelcos & 56 & 10 & 15 & 117 & 13 & 10 \\
Toro Muerto & 17 & 2 & 0 & 35 & 8 & 0 \\
\hline Total & 364 & 64 & 48 & 549 & 66 & 135
\end{tabular}

El análisis de la información cualitativa de los padrones - como la concentración o dispersión de los apellidos y de las clasificaciones socioétnicas- es igualmente demostrativo de los cambios ocurridos en tres décadas. En 1767 predomina la dispersión de los apellidos en Salanita, Santa Rosa y Atiles, sugiriendo la radicación reciente de los pobladores y la inexistencia de grupos de parentesco articulados. Por otra parte, la todavía escasa incidencia cuantitativa de los agregados influye en la homogeneidad de las etiquetas étnicas aplicadas a los individuos censados. Salvo los Roldán, «mestizos» de Solca, los Aguileras, «pardos» de Toro Muerto y los «indios» de Atiles, los «españoles» dominan en el resto de las estancias. 
Significativamente, algunos de estos datos aparecen invertidos en 1795. Por lo menos en cuatro casos (Solca, Macasín, Chepes y Malanzán) se pasa de la homogeneidad de apellidos a la dispersión, mientras que en otros tres (Salanita, Santa Rosa y Atiles) detectamos el proceso opuesto. De la misma manera, la incorporación de numerosos agregados diversifica la coloratura de los habitantes: el censista de 1795, mucho más sensible al registro de los mestizajes que su predecesor, mantuvo la calidad «baja» de los Roldán (Solca) y de los Aguileras (Toro Muerto) e hizo «descender» a los Ruarte de Chelcos, a quienes sindicó como mulatos y mestizos. Pero sobre todo, registró indios y mulatos a granel entre los agregados, incluidos los del extinto pueblo de indios de Atiles.

Este bosquejo de trazos gruesos, estas huellas desvaídas que los censos recogen, esconden historias diversas de azares biológicos, usurpaciones y resistencias. Así por ejemplo, los campos de Chepes y Malanzán fueron perdiendo sus originarias identidades Tello y Ávila porque la descendencia de los fundadores fue predominantemente femenina. Por eso, en 1795, de las once «casas» registradas en Chepes, apenas un par tienen como cabeza a un Tello. En Malanzán la situación era aún más extrema y si, al igual que en Chepes, el condominio estaba integrado en 1767 por las hijas mujeres de Josep Antonio Ávila y sus respectivos yernos, en 1795 solamente tres personas adultas recordaban el apellido del patriarca. ${ }^{30}$ Cerrando el siglo, eran los Peñaloza, los Vera y los Cabezas — todos hombres localmente poderosos-quienes mejor identificaban el condominio de Malanzán.

En cambio, en otros sitios el signo de los cambios fue el despojo liso y llano. Aquí entran Salanita y Santa Rosa, aguadas anejas de Ulapes y Chepes y también Solca, Macasín y el pueblo de indios de Atiles. Veamos los casos con más detalle.

En 1767, sólo reconocemos la aguada de Salanita por la presencia de Catalina Alcaraz (viuda de Juan Villalta, comprador de la aguada) y de sus hijos mientras que en 1795 viven allí don Domingo y don Marcos Ocampo, en compañía de sus agregados. ${ }^{31}$ Un pleito judicial nos permite asomarnos a un complejo proceso de avance de la propiedad individual pero también de negociaciones y resistencias que iluminan lo sucedido en el interín. En

30 El hijo varón de Josep Antonio Ávila vivía en la estancia de Guadalupe, no muy lejos de Malanzán. Como se verá luego, no por ello se desentendió de los asuntos de su condominio de origen.

31 Otras cuatro familias son registradas a continuación, pero ignoramos sus vínculos, sea con Catalina que con los Tello. Este caso, como otros, abre interrogantes sobre las formas de acceso de «extraños» a los condominios en ausencia de «derechos y acciones» o vínculos de agregaduría. 
principio, los «nuevos dueños» de Salanita eran parientes del presbítero Josep Nicolás Ocampo quien, con la anuencia de Catalina Alcaraz - fallecida a poco de iniciado el litigio - y el apoyo de los Tello, litigaría contra don Clemente Galván, denunciante de esas tierras en 1790. Gracias a los alegatos cruzados de Ocampo y de Galván, sabemos que el sacerdote comenzó defendiendo los derechos de la viuda, «dueña legítima»e ignorante de la necesidad de formalizar sus derechos de propiedad. ${ }^{32}$ Tres datos fundamentales nos interesa rescatar aquí: que Ocampo poseía ganado en Salanita (o sea que, de hecho, fungía como condómino de Catalina), que procuró posteriormente consolidar sus derechos sobre aquellas tierras movilizando a sus «domésticos» (sic) para impedirle a Galván el acceso a la propiedad y que el principal argumento utilizado para legitimarse como propietario fue la considerable antigüedad de la merced de Ulapes (de la que Salanita era considerada aguada dependiente). Para jugar esta última carta - que resultó victoriosa- Ocampo contó con el favor de los Tello, quienes adujeron su «genial rusticidad» y lo nombraron su representante. ${ }^{33}$

La alianza entre Ocampo y los condóminos de Ulapes abre no pocos interrogantes, que los alegatos del sacerdote no terminan de disipar. En tanto que el discurso del sacerdote fue serpenteando entre los derechos individuales y los colectivos, sus intervenciones parecen, a primera vista, contradictorias: si en las iniciales prima la defensa de los derechos de la viuda, en las posteriores se enfatizan su reciente posesión personal y los antiquísimos derechos colectivos de sus compartes los Tello que - consideraba Ocampo- lo amparaban también a él.

Don Josep Nicolás Ocampo no era pariente de los Tello ni de Catalina Alcaraz. Suponemos que fueron su lugar social, sus acuerdos con la viuda y sobre todo sus prácticas - la ocupación del terreno con el ganado de su marca a través de un grupo de agregados (los alegados «domésticos») que le respondía-, legítimas a ojos de los condóminos, las que le habilitaron la posesión de Salanita. En todo caso, los datos del padrón de 1795 sugerirían que para los herederos de la difunta «dueña» apenas si quedó un lugar

32 AHPC, 2.75.1.

33 «Sea notorio (...) como nos de la una parte don Juan Josef Tello y de la otra don Cayetano Tello, don Lucas Tello, Don Francisco Torino y Antonio Sárate, todos interesados y poseedores en el paraje y estancia de Ulape y Salanita damos y conferimos todo nuestro poder a don Jp Nicolás de Ocampo (...) (para) la defensa del dicho paraje Salanita contra las invasiones de Clemente Galván que con errada presuntiba de ser este realengo con formal denuncia ante el señor subdelegado de la ciudad de La Rioja ha inquietado y aun prosigue perturbando nuestro antiguo derecho en el citado paraje». AHPC, Esc. 2.75.1. 
subordinado: solamente dos hijas suyas son registradas y en calidad de «agregadas» de los Ocampo. En cuanto a los Tello, Galván no dejó de notar que «los moradores de Ulapes [...] quisieron introducirse» para impedirle poblar la estancia. Aunque el denunciante sospechaba que Ocampo se encontraba detrás del asunto, no sería aventurado suponer que el disfrute de Salanita incluyese también a los Tello de Ulapes. O sea, o bien que la pasada subdivisión por venta de las dos estancias rigiera ciertos derechos ( $i$ a las aguadas y pasturas?) pero no otros (¿la venta o traspaso de los mismos?) o bien que un arreglo posterior entre los Ocampo y los Tello hubiera recuperado Salanita para su uso común.

En cualquier caso, si Catalina Alcaraz, los Tello y el presbítero Ocampo realmente habían sido condóminos y como tales combatieron las pretensiones de Galván, eso no los convertía en iguales. Los Tello eran campesinos prósperos y de antiguo arraigo, Ocampo detentaba el liderazgo natural de los párrocos (además de ser el único letrado del grupo), Catalina Alcaraz era «pobre de solemnidad» y sus hijos quedarían más pobres que ella. Y aquí estamos hablando solamente de los «compartes» propietarios ¿qué lugar ocupaban los agregados de los Tello y los Ocampo, además velar por los derechos de sus protectores?

También la mudanza completa de la población de Santa Rosa entre un censo y otro obedecía a un cambio de dueños. Ya se dijo que fue una de las condóminas de Chepes quien opuso su reclamo contra el denunciante Manuel Fernández Cabezas, argumentando haber aportado con su dote los terrenos que en aquel momento poblaba su ganado. El deslizamiento discursivo entre lo particular y lo comunitario es notable en los dichos de Ana María para quien los terrenos en disputa era «propios míos, habidos por mis antecesores y pasados a ntra cuenta de mi legítima dote». Entendemos que al decir «nuestra cuenta» Ana María se refería al condominio de su familia política. ¿Le habrían «devuelto» sus compartes los Tello el uso exclusivo de Santa Rosa a partir de su viudez o bien, como sostuvieron las autoridades, se trataba de tierras «directivamente realengas», usurpadas y cedidas a la muchacha casadera por la familia Brizuela para que «formara derecho» en ellas?

Aunque las autoridades capitulares no le reconocieron a Ana María (y por extensión a los Tello) sus derechos sobre Santa Rosa, lo cierto es que el traspaso sólo pudo concretarse después de la muerte de la viuda y del denunciante. En 1799, el hijo de don Manuel anunció que había llegado el momento puesto que «habiendo fallecido dicha Señora cesó también la 
perturbación» ya que «el principal poseedor de Chepes don Nazario Tello no se oponía» (itálica nuestra). ¿Qué significaba aquella distinción? En rigor, Nazario ni siquiera era oriundo de Chepes sino de la aguada de Ambil, donde seguían viviendo sus hermanos y su parentela por línea materna. ¿Tuvo acaso que regresar a Chepes para reasumir sus derechos por vía paterna - y tal vez un lugar de autoridad - en el campo común? ¿Fue la ausencia de adultos varones en Chepes el motivo aquel regreso? Aunque no contamos con más información, hipótesis como las expuestas parecen verosímiles.

Para Solca y Macasín las «fotografías» de los padrones nos muestran recambios algo menos radicales que los de Salanita o Santa Rosa. Los Roldán dominaban en Solca en 1767 y lo seguían haciendo en 1795 mientras que en Macasín seguía manteniéndose Roque Jacinto Ávila con su familia. Ya se dijo que Solca pasó, en fecha incierta, al dominio de don Gualberto de la Vega, un influyente señor local y que el campo de Macasín quedó en manos de don Prudencio Quiroga. ${ }^{34}$ Sin embargo, la condición de propietarios de los Roldán y de los Ávila era cuestionada desde tiempo atrás y por otros personajes, que no fueron los que finalmente triunfaron.

En efecto, en 1785, María Rodríguez viuda de Roldán, Feliciano y Bartolomé Roldán y Domingo, Roque Jacinto y Francisco Ávila, condóminos de Solca y Macasín, se sumaron a un heterogéneo frente de litigantes que contenía también a las familias de tres humildes soldados y a los representantes de dos poderosos linajes locales - los Pereira y los Peñaloza-. ${ }^{35}$ La intención era doblegar las ambiciones de un enemigo común — don Josep Antonio Mercado y Reynoso- que incluía entre sus reclamos las aguadas en cuestión y que mantenía a los Ávila como «arrendatarios en sus propias tierras». Este pleito terminó por resolverse a favor de los Pereira y de los Peñaloza mientras que a los «Pobres de Jesucristo», como se autoproclamaron estos campesinos, sólo se les concedió la posibilidad de apelar de la que, al parecer, no hicieron uso. ${ }^{36}$

34 AHPC, 2.99.9

35 Boixadós y Farberman 2011.

36 En 1743, don Francisco Mercado y Reynoso, descendiente del primer beneficiario de la merced de Solca, había tomado posesión del «paraje de Macasín» «contradiciendo verbalmente a Antonio Roldán y Luis de Ávila». El litigio continuó con Asencio Roldán, considerado intruso por «no comprehenderse Macasin en la compra qe hizo» hasta que en 1758 el alcalde de Hermandad ordenó el lanzamiento de Fernando Roldán y de Luis Ávila de las tierras de sus mayores. AHPC, 2.61.7. f 47. Sin embargo, no fue hasta la intervención de Josep Antonio Mercado y Reynoso que, siguiendo el relato de los «Pobres de Jesucristo», se hizo lugar a las pretensiones de los antiguos dueños de la merced. 
Sin embargo, ni Roque Ávila en Macasín, ni los tres Roldán de Solca fueron empadronados como agregados en 1795. Aunque su situación subordinada es evidente, cabe preguntarse si los antiguos grupos de parentesco conservaron derechos parciales sobre las tierras, algo así como un antecedente de los «derechos y acciones» del siglo XIX ${ }^{37}$ Como sea, hacia 1795 la comunidad era ya inexistente en Macasín mientras que en Solca, la «compañía» de don Juan Gualberto Vega, con su séquito de esclavos y agregados, autoriza a pensar que a los Roldán no les cabían las principales decisiones en el campo común. Un documento tardío - la (denegada) solicitud de María de la Cruz Roldán a la justicia eclesiástica — confirma este final poco feliz. ${ }^{38}$ Corría 1813 y esta «vecina del lugar de Solca», por haber «venido sus descendientes en alguna pobreza», reconocía la pérdida del patronato de la capilla que su familia custodiaba desde «inmemorial tiempo». ${ }^{39}$ Siguiendo un procedimiento desconocido por el derecho canónico, el título había recaído interinamente en don Juan Gualberto de la Vega «quien pretende hacer que se le pague por justicia la sepultura de dho mi padre, siendo así que se debe tener por estimada la prelacía del fundador de dha capilla por haberla trabajado mi antecesor a costa de su propio peculio». Como podemos comprobar, el despojo de los Roldán no se había detenido en los bienes materiales, también los simbólicos habían quedado por el camino...

Todos los ejemplos referidos hasta ahora apuntan a conflictos con personajes externos a los condominios que, además, parecen estar operando con una lógica nueva, especulativa y mercantil. Por contraste, los casos de Malanzán / Atiles y de Chelcos / Toro Muerto permiten aproximarnos a la cara oscura de los campos comunes, a los pleitos domésticos que, al decir de Sarmiento, tenían en vilo aquel «país indiviso» de Los Llanos de La Rioja.

\section{Semilleros de pleitos}

El lector ya conoce sumariamente la historia del soldado Juan Ruarte, comprador de la merced de Chelco y vencedor en la puja por los derechos

37 Sí fueron registrados entre los agregados de otros sitios sus parientes Francisco y Pedro Avila. También hay un núcleo de agregados de apellido Roldán en Tama pero no podemos confirmar su vinculación con el grupo de Solca.

38 AAC, 34.III.1813.

39 Josep Roldán, el soldado fundador, había edificado la capilla de Solca a principios del siglo XVIII. Fue uno de los argumentos que en un pleito criminal su hijo esgrimió para afirmar su calidad de español que el alcalde de hermandad le negaba en vistas de que «su mismo rostro y pelo» acusaban su condición de indio. Analizamos este expediente en Boixadós y Farberman, 2011. 
sobre la aguada aneja de Toro Muerto. ${ }^{40}$ También algo se adelantó acerca de la estabilidad de las familias que poblaban aquellas aguadas y que permanecen distintas en los dos padrones: mientras que los descendientes de Juan Ruarte predominaban en Chelco, en Toro Muerto lo hacían los «mulatos» Aguilera.

Sin duda estas dos aguadas integraban un «campo común»y así lo denominaron los actores, dejándonos la única mención que conocemos en fuentes coloniales. Menos claras, en cambio, son las relaciones que vinculaban a los Ruarte con los Aguilera: ni el parentesco ni la agregaduría pueden inferirse de nuestros datos y tampoco encontramos referencia alguna sobre una posible venta. Quizás Juan Ruarte les habilitó a los Aguilera el acceso a la aguada para preservar los derechos de su propia familia: ¿gozarían acaso de una posición intermedia entre parientes y agregados? Como fuera, cuando en 1785 la denuncia de un tal Gallardo puso en riesgo la permanencia de todos los compartes, los descendientes de Juan Ruarte solicitaron colaboración a los Aguilera.

La denuncia de los terrenos debía contrastarse con la exhibición de unos títulos (los de la merced comprada por Juan Ruarte hacia 1700) extraviados desde hacía tiempo. Como el único documento disponible era la mentada declaración de testigos de 1733, le tocó a don Pedro de Arze, «alférez de uno de los regimientos de milicias de Los Llanos» y esposo de una nieta de Juan Ruarte, completar los datos faltantes para la composición, acudiendo a la memoria y a la buena voluntad de sus vecinos. Fue en este trámite que los larvados conflictos que dividían a los condóminos se desataron.

En efecto, según Pedro de Arze, los Aguilera comenzaron demostrando «desinterés» por sus gestiones, lo que le animó a solicitar la mensura a título individual. ${ }^{41}$ Pero los enfrentamientos no terminaron allí. Una nueva petición de Pedro de Arze podría indicar que la indiferencia de sus compartes por los títulos escondía otra intención: la de «emancipar» la aguada de Cabeza del Toro Muerto de la merced de Chelco. Para ello, siempre según este personaje, los Aguilera habrían contado con la complicidad de su condómino de Chelco, Esteban Quintero. En sus palabras

40 AHPC, 2.98.94.

41 Según Pedro de Arze los Aguileras se habían «escusado con frívolos pretestos en género de desprecio de las reales determinaciones (...) por cuio motivo he retardado el comparendo en este su juzgado». Solicitaba en consecuencia «instar a la citada composición por mí solo individuo sobre todas las pertenencias suso citadas». AHPC, 2.98.94. 


\title{
EL «PAÍS INDIVISO». DERECHOS DE PROPIEDAD
}

\begin{abstract}
«Esteban Aguilera, mi convecino, ganó providencia del mismo juzgado para mensurar las tierras pertenecientes a la parte nombrada la Cabeza del Toro Muerto en que habita, agregándose por demasía y con pretexto de compra que dice le hizo a Esteban Quintero de una aguada que no pudo ni debió venderla»
\end{abstract}

Tanto Aguilera como Quintero fueron citados a La Rioja pero ninguno de ellos compareció, dejándonos a solas con Pedro de Arze y sus impugnaciones. Que confluían en un único y eficaz argumento: un condómino no podía vender por su cuenta una porción de un terreno común. Las dos aguadas era indivisibles y la misma historia de la propiedad llevaba la marca de la permanencia antigua de los Ruarte. ¿Se habría arrogado Esteban Quintero prerrogativas de «condómino principal» como lo había hecho antes Pedro de Arze al denunciar las tierras comunes a título individual? En todo caso, esta vez prevalecieron los intereses colectivos y la mensura y composición — que se realizaron por la totalidad del terreno- fueron firmadas en conformidad por representantes de las dos aguadas.

El litigio por Toro Muerto enfrentó a pobres contra pobres. La mayoría de mulatos que don Cándido Sotomayor registró en 1795 en ambos sitios, la ausencia de agregados en las «casas» de los Ruarte y de los Aguilera y la modestia del patrimonio en disputa nos lo confirman. Por el contrario, Malanzán se diferenciaba de cualquier campo común de Los Llanos por la notabilidad de buena parte de los jefes de familia, la dimensión de sus séquitos y la profusa ocupación de aguadas aledañas por grupos emparentados con los condóminos. Tanto para empezar, don Cándido Sotomayor distinguió con el «don» a 14 de los veinte jefes de familia (sin contar a otros cuatro localizados en las aguadas próximas de Río Salado, Lugar de los Molles y Potrero de los Veras) y, como contrapartida, registró a un cuarto de la población de Malanzán en calidad de agregada. Otras fuentes nos confirman el prestigio de varios de los yernos de Josep Antonio Ávila: don Esteban Vera fue juez comisionado, don Josep Orihuela oficial militar, mientras que los Peñaloza, como airadamente señaló uno de los condóminos, ventilaban públicamente sus aires de nobleza, eran muy ricos y tenían a un «doctor» (el sacerdote Vicente Peñaloza) entre sus filas.

Los tres pleitos que nos permiten ingresar al conflictivo mundo de Malanzán giran alrededor de una misma figura: don Nicolás Peñaloza, abuelo del Chacho y primera fortuna ganadera del curato en el ranking decimonónico del informe de 1805. En breve síntesis, los expedientes que analizaremos tratan sobre una disputa con don Francisco Vera (1777), 
sobre la nulidad del matrimonio de su hijo Esteban (1797) y sobre un conflicto por las «sobras» de Atiles (1803).

La cuestión del honor (individual y de la «casa»), así como las lealtades hacia los Peñaloza (aquí expresadas en la movilización de testigos de diversa condición) están en el centro de los pleitos más tempranos. El episodio de 1777 comenzó con la detención de un protegido de don Nicolás - el «muchacho» Celidonio Banegas - a causa de una deuda impaga. ${ }^{42}$ Urgido por los servicios de Celidonio, don Nicolás se ofreció a saldarla, pero el alcalde rechazó la propuesta. Entonces, una agria discusión condimentada con insultos y golpes enfrentó a los dos compartes, a la vista de una nutrida concurrencia.

Sin duda, lo más irritante para don Francisco Vera fue el desconocimiento de su investidura. Según declararon él y otros presentes, tanto don Nicolás como su padre Francisco, le exigieron la vista de sus títulos para luego reprocharle que administraba justicia «sólo para su casa». Los testigos que narraron el incidente — dos de los cuales habían acompañado a Vera para prender a don Nicolás - dejaron en claro su conflicto de lealtades, aunque la balanza - como no dejó de notarlo el comisionado - se inclinara en favor de Peñaloza. La investidura política de don Francisco Vera no conseguía eclipsar la influencia informal de su contrincante sobre sujetos que, en sus palabras, o bien eran sus «domésticos» o bien sus «comensales». ${ }^{43}$ ¿Cómo podía, de lo contrario, explicarse el desconocimiento de las órdenes del comisionado y la «parcialidad» de las declaraciones de los testigos?

Por cierto, los resentimientos entre los dos señores de Malanzán tenían una larga historia, que la disputa por Celidonio no hizo más que reavivar. Don Nicolás recordó la difamación de su difunta esposa y también Vera - al tachar a su rival de «cornudo» en el fragor de la pelea- trajo a la memoria de los presentes aquel episodio humillante. Según recordaron los testigos, esa antigua discusión había sido resuelta con la intercesión del párroco, que los había hecho compadres para sanar las heridas. Ahora que volvían a abrirse, Vera, que sostenía «no presumir de noble como los Peñalozas» sino haber adquirido la nobleza «con sus buenos procedimientos», consideraba justo «que don Nicolás de Peñaloza me deba tratar con atención y no con desprecio».

42 AGN IX.42.1.5.

43 Es significativo que -incluso acompañando como «soldados» al alcalde- Joaquín y Raimundo Cabezas, Hermenegildo Bergara y Josef Ochoa se hubieran negado siquiera a acercarse a don Nicolás. Sólo se atrevieron a prender a Celidonio Banegas. 
¿Puede leerse la solicitud de nulidad de matrimonio de Esteban Peñaloza como una variación sobre el mismo tema ${ }^{44}$ ? En 1797, este joven de 26 años — que ya había procreado un hijo con su condómina y pariente Úrsula Riveros- formalizó su vínculo frente al altar. No queda claro cuánto de espontáneo tuvo el matrimonio: un testigo menciona la mediación de una condómina, mientras que otro se refiere a que «estando (Esteban) para montar en un caballo (y escapar), se juntaron unas mujeres y lo agarraron para que no se fuese» y cumpliera con su promesa. El caso es que la unión horrorizó a don Nicolás Peñaloza que, desde tiempo atrás, intentaba persuadir al cura para impedirla.

Sin dudas se trataba de un matrimonio desigual: los Riveros eran muy pobres y los Peñaloza acaudalados. Pero don Nicolás prefirió desacreditar a la novia convocando a sus condóminos para que informaran sobre supuestos escandalosos romances de Úrsula. Aunque los testigos reconocieron hacerse eco de rumores, sus declaraciones confluyeron en el retrato de «pública ramera» que tan repugnante le hacía la boda a don Nicolás.

Para restablecer el orden, el cura reunió una nueva información que buscaba vincular a la muchacha a una casa pobre pero honrada. Más aún, se apuntaba que a los abuelos de la novia les cabía el honor de haber construido «a costa de su propio peculio, con agregación de algunas limosnas, la Iglesia de su vecindad». Pero sobre todo, como dijeron a una voz los testigos, «si no se efectúa el matrimonio que ha intentado, se an de seguir inquietudes en casa de la otorgada, muchos los escándalos y sumo el deshonor de la pretendida». Por mucho que le pesara a don Nicolás Peñaloza, la boda era el precio de la paz en aquel atribulado vecindario. ${ }^{45}$

Nuestro último expediente es la apelación de un grupo de compartes de Malanzán para impedir la transferencia de las sobras del pueblo de Atiles a don Nicolás Peñaloza, titular del pueblo desde $1779 .{ }^{46}$ La protesta de un grupo de condóminos de Malanzán, inicialmente liderado por don Luis Ávila y posteriormente por don José Orihuela, apuntaba a defender los intereses de «una multitud de infelices» que una decisión favorable a Peñaloza «arrojaría de sus hogares» y «privaría de sus sembrados y labranzas». ${ }^{47}$ ¿Serían

44 AAC. 198.180.

45 Fue de la unión de Ursula y Esteban que nació el famoso caudillo decimonónico Angel Vicente «Chacho» Peñaloza.

46 AGN. IX.23-5-6.

47 Don Luis Ávila no vivía en Malanzán pero mantenía derechos en el condominio por vía paterna. 
aquellos «infelices» los agregados personales de ciertos condóminos de Malanzán? Es lo que imaginamos aunque nuestras fuentes silencien sus voces.

En todo caso, en 1806 la apelación fue escuchada y el juez pedáneo comisionado para notificar a Peñaloza que sus condóminos debían «seguir en su pacífica posesión hasta en tanto su alteza resuelva otra cosa». Así las «sobras» de Atiles continuaron integrando la propiedad comunera de Malanzán y sólo las tierras del pueblo - amén de otras que fue adquiriendo en el interín, como las de La Hediondita, la «merced» más vasta de Los Llanos- se mantuvieron bajo el control exclusivo de don Nicolás.

¿Qué rescatar de este conjunto de pleitos? Lo primero que sobresale es el alto nivel de conflictividad entre los compartes, forzados a dividir sus lealtades entre los hombres fuertes. Una permanente división en facciones -necesitadas de reconciliación, como la que los sacerdotes intentaron por lo menos dos veces y la justicia capitular procuró otras tantas-, signó en las coyunturas estudiadas la dinámica de esta vecindad tan poco armónica. La desigualdad y la fragmentación de los intereses económicos de los compartes (con sus derechos dispersos en otra propiedades) así como la dominación que éstos se disputaban sobre los «domésticos», los agregados y hasta los mismos indios que se mantuvieron en la órbita de la estancia, convirtieron a Malanzán en un auténtico «semillero de pleitos» y relaciones sociales clientelares. ${ }^{48}$ Con todo, incluso los hombres más fuertes podían perder, especialmente si se creaban enemigos por todas partes: ni siquiera don Nicolás Peñaloza, el hombre más rico de Los Llanos, pudo esquivar la prisión por herir a Vera, ni tampoco impedir el matrimonio de su hijo. Y aunque en su vida logró acumular muchas tierras, no tuvo más remedio - hasta donde sabemos - que compartir las sobras de Atiles con sus condóminos de Malanzán.

\section{Conclusiones}

Existe una vasta literatura sobre los múltiples «otros modos de poseer» que el derecho liberal eclipsó o invisibilizó. Parte de ella se ocupa de la península ibérica, donde extensas regiones se hallaban bajo regímenes

48 En este sentido, no es descabellado pensar que una de las razones del rechazo que don Nicolás sentía por su nuera se afianzara en la acumulación de derechos sobre Malanzán en el grupo de los Riveros. 
de propiedad colectiva, regímenes cuestionados desde el siglo XVIII. ${ }^{49}$ A modo de epílogo y para articular algunas conclusiones sobre nuestro caso, nos interesa puntualizar cuatro cuestiones:

1.-El contraste entre propiedad privada y formas más cercanas a la posesión, que priorizarían los intereses del grupo por encima de los individuales. Esto no suponía necesariamente igualitarismo pero sí formas de gestión específicas, a menudo depositadas en instituciones (por ejemplo, los municipios).

2.- - La identificación de estos modos alternativos de poseer con una cultura jurídica popular basada en la costumbre. El tiempo y las comunidades habrían legitimado determinadas prácticas (de pastoreo, recolección, etc.) que, en algunos casos, podían cristalizar en normativas (generalmente de alcance local). Esta cultura jurídica alternativa lo habría sido por sus bases sociales pero también por las necesidades comunitarias de organizar autónomamente sus derechos y obligaciones.

3.- La connaturalidad entre los terrenos comunes y determinados ambientes, bajo ciertas condiciones de asentamiento y de estabilidad demográfica. «Comunal» suele aparecer como sinónimo de «terreno inculto», de bosque, de zona montañosa, funcional a un patrón de ocupación disperso.

4.- - La inclusión de un conjunto restringido de beneficiarios y la exclusión de otros sujetos. Por ejemplo, los vecinos o los indios tributarios, legítimos beneficiarios de ejidos y sementeras comunitarias en los pueblos de indios.

Durante la colonia, la propiedad comunera se impuso en Los Llanos como una estructura agraria dominante, manteniendo su primacía en el siglo XIX. Aún más, según datos recogidos por Adrián Mercado y Reynoso, en 1999 las «mercedes» ocupaban todavía 3.000.000 de hectáreas. Por lo tanto, no se trataba - ni se trata - de una forma de propiedad residual, cuanto menos en las «costas» llanistas. En contraste, cuando fue posible la colonización de las áridas llanuras más apartadas de las sierras, la propiedad individual prevaleció. ${ }^{50}$

¿Qué razones explican la centralidad del sistema de campos comunes? A nuestro juicio, además de su funcionalidad en el árido, parte de la respuesta apunta a las peculiaridades del proceso de poblamiento y al perfil

49 Tomo la expresión de Paolo Grossi (1981). Sobre España, entre muchas otras contribuciones, Congost 2007a, Pérez Picazo 2003, Rey Castelao 1997, Iriarte Goñi 1998, Moreno 1993 y 1998.

50 Denis 1987 (1920). 
social predominante de los colonos. La propiedad común, postulamos, sería una estructura típica - aunque, por supuesto, no exclusiva- de cristalización del poblamiento pionero. Una vez agotadas las posibilidades de expansión hacia otras aguadas - y por ser el pastoreo la actividad económica con mejores posibilidades - la propiedad indivisa contaba con todas las condiciones para triunfar sobre otras modalidades.

La historiografía, hemos reseñado, suele contraponer uso común y propiedad privada. Sin embargo, los compartes de nuestros ejemplos descendían de un propietario (y casi todos conservaban sus antiguos títulos) y se proclamaban como tales. Cierto es que la propiedad recibida como merced (o adquirida a un beneficiario) podía mejorarse «formando derecho» sobre aguadas cercanas, quizás sin formalizar la ocupación. Nos inclinamos a pensar que por mucho tiempo existió una cierta indefinición en los límites entre la propiedad y la posesión y que, mientras no existió presión demográfica y Los Llanos se mantuvieron relativamente aislados, la ambigüedad favoreció a los pioneros. Sin embargo, esa misma indefinición fue luego aprovechada por los denunciantes de tierras que, como demostramos, en no pocas ocasiones lograron ser atendidos...

Los casos expuestos coinciden con una coyuntura que habilitó la redefinición de los derechos de propiedad. En las páginas que siguieron, asistimos a la victoria de personajes influyentes como Nicolás Peñaloza, Prudencio Quiroga y Gualberto de la Vega pero también a algunas resistencias colectivas, como la de los «Pobres de Jesucristo» de Solca y Macasín y a otras individuales - como la de Catalina de Alcaraz y Ana María Brizuela-. Entrevimos negociaciones entre los Tello y el cura Ocampo, y seguramente también entre los compartes de Chelcos y Toro Muerto, aunque sólo nos enteremos de la etapa final de los arreglos. Por último, los indios de Atiles parecen haber aceptado resignadamente su suerte (aunque quizás sólo se tratara de un desenlace anunciado ya que la dispersión de la comunidad parece muy anterior al remate de 1779).

Sin embargo, aunque el conflicto le permita al historiador atisbar lo normal, debemos reconocer que las prácticas de los condóminos siguen resultándonos opacas y que el examen de los expedientes nos ha dejado en este plano pocas certezas y muchos interrogantes. Una de las certezas es que, aun tratándose de campos comunes, diversos derechos de propiedad se hallaban en tensión. ${ }^{51}$ Las intentonas de don Pedro de Arze o de los

51 Congost 2007b, 59. 
Aguileras de Toro Muerto por componer a título individual, los avances de don Nicolás de Peñaloza sobre Atiles y sus sobras en oposición al interés de sus condóminos de Malanzán, el uso exclusivo que Ana María Brizuela decía hacer de la aguada de Santa Rosa, los deslizamientos permanentes entre el yo y el nosotros del cura Ocampo son algunos indicios de ello. Pero las dudas siguen en pie. Ya sabíamos que la comunidad regía sobre el disfrute común de las pasturas pero que las construcciones, los terrenos cultivados y los animales eran de propiedad individual. ¿Cómo se saldaban las diferencias en vistas de la desigualdad material de los condóminos y de la escasa carga ganadera que podían soportar estos campos? La dote aportada por Ana María Brizuela, tierras que al parecer eran de su disfrute exclusivo, ¿señalaba una norma comunitaria que se replicaba en otros campos comunes? ¿Qué implicaba ser «principal poseedor» de un campo común, como se dijo que lo era Nazario Tello? ¿Excedían sus decisiones la regulación del acceso a tierras, de introducción de «extraños», de cesiones o incorporaciones de tierras?

Interrogantes no menos significativos se abren también en relación a las jerarquías, no sólo entre condóminos sino también entre «casas», la unidad de registro del censista de 1795 que, por cierto, iba mucho más allá de la corresidencia. Sabemos que no existía necesariamente igualdad económica ni social entre los condóminos aunque quizás sería más ajustado hablar de «casas» que de sujetos. Nuevamente lo individual y lo colectivo se intersectaban. ¿Quién podría dudar sobre las lealtades personales que don Nicolás Peñaloza, don Francisco Vera o don Josef Orihuela habían conquistado y podían movilizar? ¿No se extendían acaso esas lealtades hacia el conjunto de la «casa»? Todas estas preguntas nos conducen a la dimensión política de este tipo de organización agraria y social. A diferencia de los comunales europeos, no existían aquí consejos que tomaran las decisiones: en Los Llanos, nuestro paisaje es de «comunidades sin pueblo». Los sacerdotes y los notables del lugar reemplazaban a las autoridades formales y aquí nos internamos en un problema espinoso, que no podemos resolver por ahora, pero que seguramente fue preparando la trama de relaciones sociales que años más tarde movilizaron las montoneras.

La propiedad comunera ha llegado hasta nuestros días. Sin negar los importantes cambios que han afectado la economía regional durante el siglo XX, lo cierto es que asombra la estabilidad del sistema, así como el reconocimiento de los campos a través de las familias situadas allí desde tiempo inmemoriales. Gracias a Gabriela Olivera, sabemos también que mecanismos similares a los que promovía la Cédula de 1754 fueron 


\section{JUDITH FARBERMAN}

también implementados tiempo más tarde bajo pretexto de «sanear» los títulos. ${ }^{52} \mathrm{Y}$ sin embargo, tampoco ese orden que se esperaba «nuevo» consiguió desplazar a esa maraña de prácticas, de derechos parciales y cruzados que no fueron solamente «semillero de pleitos» sino también expresión de solidaridades y cohesión social.

Recibido el 13 de junio de 2012

Aceptado el 4 de abril de 2013

52 Olivera, 2000. 


\section{Anexo}

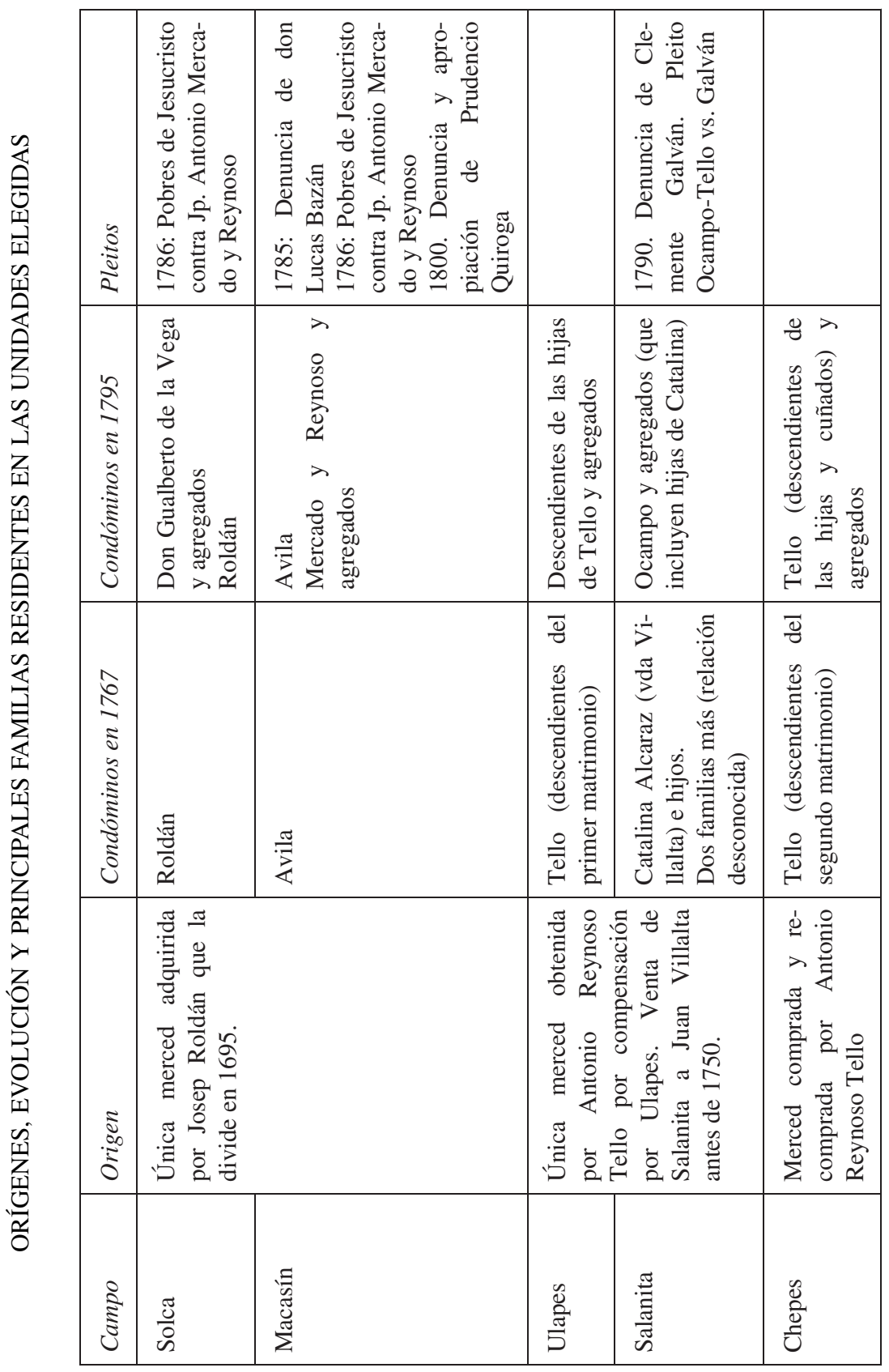

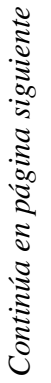




\section{JUDITH FARBERMAN}

\begin{tabular}{|c|c|c|c|c|}
\hline 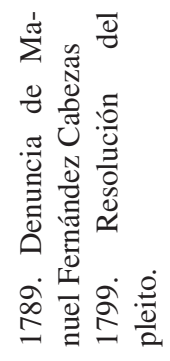 & 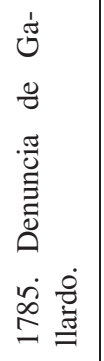 & 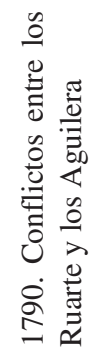 & & 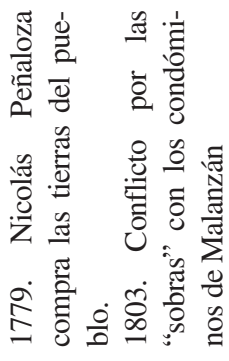 \\
\hline 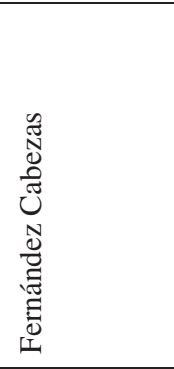 & 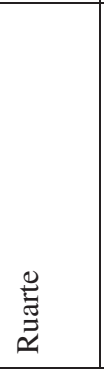 & 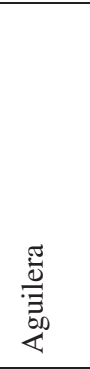 & 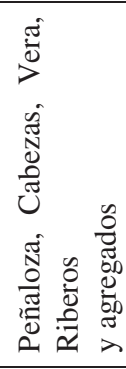 & 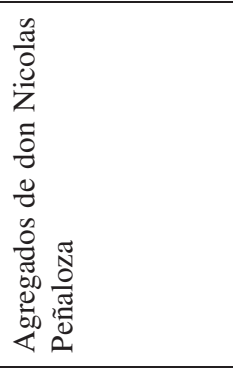 \\
\hline 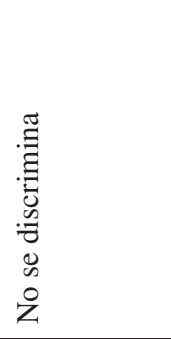 & 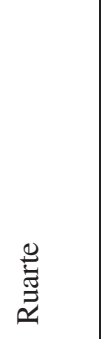 & 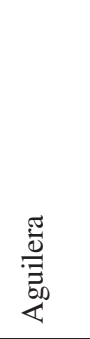 & 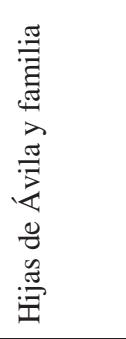 & 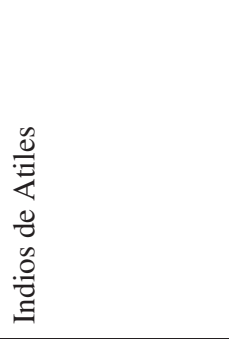 \\
\hline 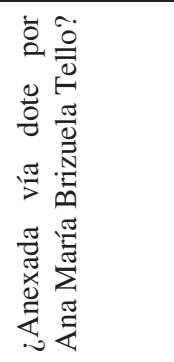 & \multicolumn{2}{|c|}{ 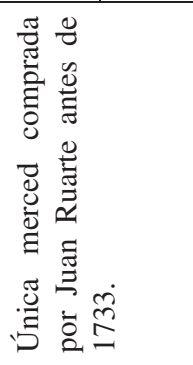 } & 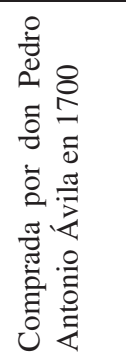 & 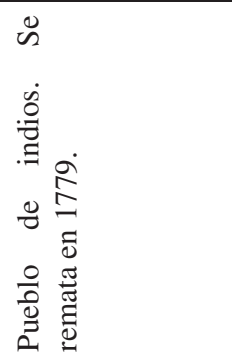 \\
\hline 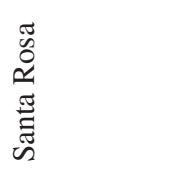 & $\begin{array}{l}\frac{0}{0} \\
\frac{0}{0} \\
\frac{0}{U}\end{array}$ & $\begin{array}{l}0_{0}^{0} \\
\sum_{0}^{0} \\
0 \\
0 \\
0\end{array}$ & 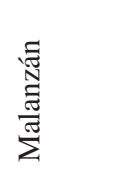 & 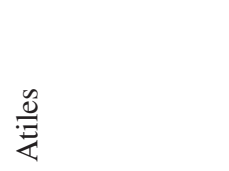 \\
\hline
\end{tabular}




\section{Bibliografía}

Boixadós, Roxana: «Los justos títulos. Contextos de conflictividad por la tierra en Los Llanos riojanos, siglo XVIII», Sociedades de Paisajes áridos y semiáridos, I, 2009, 185-208.

Boixadós, Roxana y Judith Farberman: «Clasificaciones mestizas. Una aproximación a la diversidad étnica y social en Los Llanos riojanos. Siglo XVIII», en Farberman Judith y Silvia Ratto (coords.), Historias mestizas en el Tucumán colonial y en las pampas. Siglos XVII a XIX, Buenos Aires, Biblos, 2009a, 79-114.

Boixadós, Roxana y Judith Farberman: «"Oprimidos de muchos vecinos en el paraje de nuestra habitación". Tierra, casa y familia en Los Llanos de La Rioja colonial», Boletín del Instituto Ravignani, 31, 2009b, 11-31.

Boixadós, Roxana y Judith Farberman: «Propietarios, agregados y Pobres de Jesucristo . Tierra y sociedad en Los Llanos riojanos en el siglo XVIII», Historia Agraria, 54, 2011, 41-70.

Congost, Rosa: «Sagrada propiedad imperfecta. Otra visión de la revolución liberal», Tierras, leyes, historia. Estudios sobre la «gran obra de la propiedad», Barcelona, Critica, 2007a, 121-157.

Congost, Rosa: «Prácticas de justicia, derechos de propiedad y actitudes de clase. El Ampurdán y el Rosellón en el siglo XVIII», Tierras, leyes, historia. Estudios sobre la «gran obra de la propiedad», Barcelona, Critica, 2007b, 219-252.

Consejo Federal de Inversiones: Estudio sobre las mercedes de Los Llanos de La Rioja, ms., 1964.

De la Fuente, Ariel: Los hijos de Facundo. Caudillos y montoneras en la provincia de La Rioja durante el proceso de formación del estado Nacional Argentino (1857-1870). Buenos Aires, Prometeo, 2007.

Denis, Pierre: La valorización del país. La república argentina en 1920, Buenos Aires, Solar Hachette, 1987.

Grossi, Paolo: An Alternative to Private Property. Collective Property in the Juridical Consciousness of the Nineteenth Century, Chicago, The University of Chicago Press, 1981.

Iriarte Goñi, Iñaki: «La pervivencia de los bienes comunales y la teoría de los derechos de propiedad. Algunas reflexiones desde el caso navarro. 1855-1935», Historia Agraria, 15, 1998, 113-142.

Mariluz Urquijo, José María: El régimen de la tierra en el derecho indiano, Buenos Aires, Perrot, 1968.

Mercado Reynoso, Adrián: Tierras, cosas, consuetudes. Formas disociadas de propiedad inmobiliaria en la ciudad de Todos los Santos de la Nueva Rioja (siglos XVI-XVIII), Rosario, UNR, 1999. 
Moreno Fernández, José: «El régimen comunal y la reproducción de la comunidad campesina en las sierras de La Rioja, siglos XVIII-XIX», Historia Agraria, 18, 1998, 75-111.

Olivera, Gabriela: Por travesías y oasis. Mercados, producción agraria y actores sociales de La Rioja (Los Llanos y Arauco, 1900-1960), Córdoba, Universidad Nacional de Córdoba, 2000.

Ots Capdequí, José: El Régimen de la tierra en la América española durante el período colonial. Trujillo, Publicaciones de la Universidad de Santo Domingo, 1946.

Palomeque, Silvia: «Circuitos mercantiles de San Juan, Mendoza y San Luis. Relaciones con el "Interior Argentino", Chile y el Pacífico Sur (18001810)», Anuario IEHS, 21, 2006, 255-286.

Pérez Picazo, María Teresa: «Propriété collective et "désamortissement" en Espagne (1750-1900)», en Demélas, Marie Danielle y Vivier, Nadine, Les propietés collectives face aux attaques libérales (1750-1914). Europe Occidentale et Amérique Latine, Rennes, Presse Universitaire, 2003, 197-215.

Rey Castelao, Ofelia: «La propiedad colectiva en la España moderna», Studia Historica. Historia Moderna, 16, 1997, 5-16.

Sarmiento, Domingo: Vida del Chacho, Buenos Aires, Rodolfo Alonso Editor, 1973.

Tell, Sonia: «Expansión urbana sobre tierras indígenas. El pueblo de La Toma en la Real Audiencia de Buenos Aires», Mundo Agrario 20, 2010, en línea.

Tell, Sonia: «Títulos y derechos coloniales a la tierra en los pueblos de indios de Córdoba. Una aproximación desde el siglo XIX», Bibliographica Americana. Revista interdisciplinaria de estudios coloniales, 7, 2011, 201-221.

Zubrzycki, Bárbara: «Herederos dueños y derechosos. Propiedad y herencia de la tierra en Asampay, Argentina». Sociedad rural, producción y medio ambiente , 4, 1, 2002, 19-27. 